\title{
MANAGEMENT STRATEGIES FOR TAIWAN RESERVOIR CATCHMENT AREAS: A CASE STUDY IN SHIH-MEN RESERVOIR CATCHMENT AREA
}

\author{
Hun-Feng Huang \\ Department of Public Administration and Policy \\ National Taipei University, Taiwan \\ $\&$ \\ Water Resources Management and Policy Research Center \\ Tamkang University, Taiwan \\ E-mail: hhf@water.tku.edu.tw \\ Hen-Chin Chen \\ Department of Public Administration and Policy \\ National Taipei University, Taiwan \\ E-mail: hcc31699@ms41.hinet.net \\ Sean Liu \\ Water Resources Management and Policy Research Center \\ Tamkang University, Taiwan \\ E-mail:Sliu@water.tku.edu.tw
}

\begin{abstract}
In Taiwan, there are 113 reservoir catchment areas delineated as public water source protection areas, covering 25\% of Taiwan's land area. Many important reservoir areas are vulnerable to global climate change, as water resources is already under increasing ecological, societal, hydrological and economic pressures. In this research, a case study of Shih-Men Reservoir catchment area management is constructed. Thirteen factors under the categories of "land use", "water quality protection", "quantity of water supply and demand", "water and soil conservation", "laws and institutions" are identified and corresponding response strategies are proposed. In order to optimize the use of limited government budgets and resources, the factors and corresponding response strategies are assessed and ranked in terms of their comparative impacts. The analytical network process (ANP) is employed in this research for quantifying multiple stakeholders' perceptions of the above mentioned factors and response strategies. The ANP results show the "national land planning" to be the most important issue, under which "the extent of land use" is the strongest factor. "Public participation" is shown to be the strategy of the highest priority, under which land development's environmental impacts need to be reviewed, and an information management platform needs to established so that value added analysis can be performed in support of catchment management strategic planning.
\end{abstract}

Keywords: Reservoir Catchment Area, Management Strategies, Analytical Network Process 


\section{Introduction}

In Taiwan, there are 113 reservoir catchment areas delineated as public water source protection areas, covering $25 \%$ of Taiwan's land area. In terms of the massive area covered by the water source preservation sites, due to constituting multiple jurisdictions, and involvement of multiple management units, factors that influence water quality and quantity control is already under increasing ecological, societal, hydrological and economic pressures. In this research, a case study of Shih-Men Reservoir catchment area management is constructed. This paper utilizes collaborative planning, through in-depth interviews with stakeholders, to construct key issues that the catchment management in Taiwan now faces. Thirteen factors under the categories of "land use", "water quality protection", "quantity of water supply and demand", "water and soil conservation", "laws and institutions" are identified and corresponding response strategies are proposed. In order to optimize the use of limited government budgets and resources, the factors and corresponding response strategies are assessed and ranked in terms of their comparative impacts. Lastly, the analytical network process (ANP) (Saaty and Saaty, 2003) is employed in this research for quantifying multiple stakeholders' perceptions of the above mentioned factors and response strategies. Additionally, investigation of recommended research and analysis development is discussed, as to provide reference for the future implementations and research tactics of the current government.

\section{Literature Review}

Utilizing content of local interviews with stakeholders as well as taking account of the compiled results of related documents, we can construct four key discussion points that the management of the preservation sites at Shih-Men reservoir now faces: "land management", "rules and regulations", "execution", and "environmental justice" (Water Resources Agency, 2009a). This includes discussion articles as follows:

(1) Land management issues

a. Illegal usage of national forests

b. Over-utilization of land

c. Compensation to areas near silt dams and preservation sites near the reservoir

d. Concurrence of preservation sites near reservoir and urban planning

(2) Issues regarding rules and regulations

a. Lack of overall planning of preservation sites and mechanism of integration

b. Lack of a platform to coordinate all levels of ministry

(3) Execution issues

a. Lack of manpower in the executive branch

b. Unable to implement laws to suppress illegal jobs due to public opinions

(4) Issues of environmental justice

a. Source of income for local residents

b. Publication of information and participation of people

\section{Hypotheses/Objectives}

In hopes of constructing five main aspects of important discussion the management of Taiwanese catchments and similar environments could now face, this paper consults in turn the aforementioned issues that water preservation sites near the Shih-Men reservoir now face and the analytically compiled results of interview records and related documents regarding Taiwanese water preservation sites (Water Resources Agency, 2009b). As such: "land use", "water quality protection", "quantity of water supply and 
demand", "water and soil conservation" as well as "laws and institutions", furthermore creates key points under these five issues for discussion.

The vast amount of area covered by the water source catchments, its constitution of multiple jurisdictions, as well as the involvement of multiple management units raises the question of how to integrate a reasonable development strategy for preservation sites. However, relying on the method of collaborative planning to supplement strategizing is a necessity, as well as being advantageous for the government to configure the most justifiable configuration for limited resources. Generally speaking, the collaborative planning procedure includes six stages in Figure 1: (1) defining the problem; (2) establishing an assessment standard; (3) developing alternative programs; (4) comparison of alternative programs; (5) selecting an alternative program; (6) conducting evaluation.

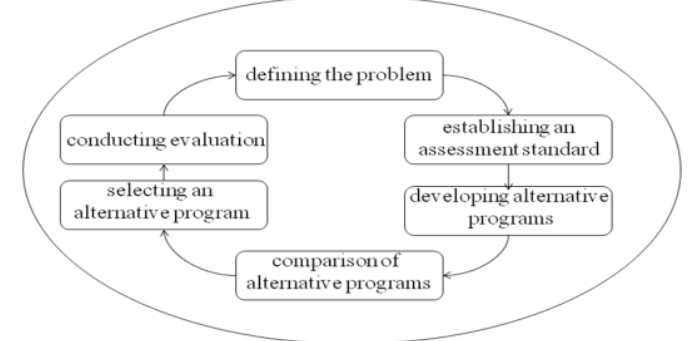

Fig. 1. Diagram of collaborative planning( Source: Patton \& Sawicki,1986: 26).

This paper uses the theory of collaborative planning as well as the Analytical Network Process (ANP). Through interviews with stakeholders affected by the policy, we recompile influencing factors regarding the management of the research on water preservation sites as well as alternative program strategies. Thus gaining a better grasp of key aspects and why influencing factors provide consultation for future government administrations and development of important strategies.

\section{Research Design/Methodology}

In order to put cooperation into practice, during the planning phase of the process, we must include the opinions of those whose interests are affected by the policy. Our research uses the classification principle by R. Mitchell et al. (1997: 872-9), which categorizes those whose interests are affected into three main traits as such: "power", "legitimacy "and "urgency". In order to understand the priorities of those whose interests are affected, the opinions of each related group are analyzed and categorized by the influencing factor of their judgments through the Analytic Network Process (ANP). Our research of the procedure of ANP's application is as shown in Figure 2, ANP's basic structure can be classified into four main points: evaluation and comparison of the systematization of complex comparisons and assessments and setting the scale, establishment of pairwise comparison of matrixes, prioritization of vectors and maximizing the eigenvalue, and testing for consistency(Saaty and Saaty, 2003). 
IJAHP Article: Mu, Saaty/A Style Guide for Paper Proposals To Be Submitted to the International Symposium of the Analytic Hierarchy Process 2014, Washington D.C., U.S.A.

In the ANP method each aspect of evaluation, influencing factors and alternative programs are independent but have the property of mutual influence(Saaty, 2001). This paper takes the mutually influencing relationship between every criteria (A-E) , 13 factors (A1、A2 ..E2、E3) and program (Alternatives, 1-8) to construct, as shown in Table $1 \&$ Figure 3, a map of the relationship network of the ANP.

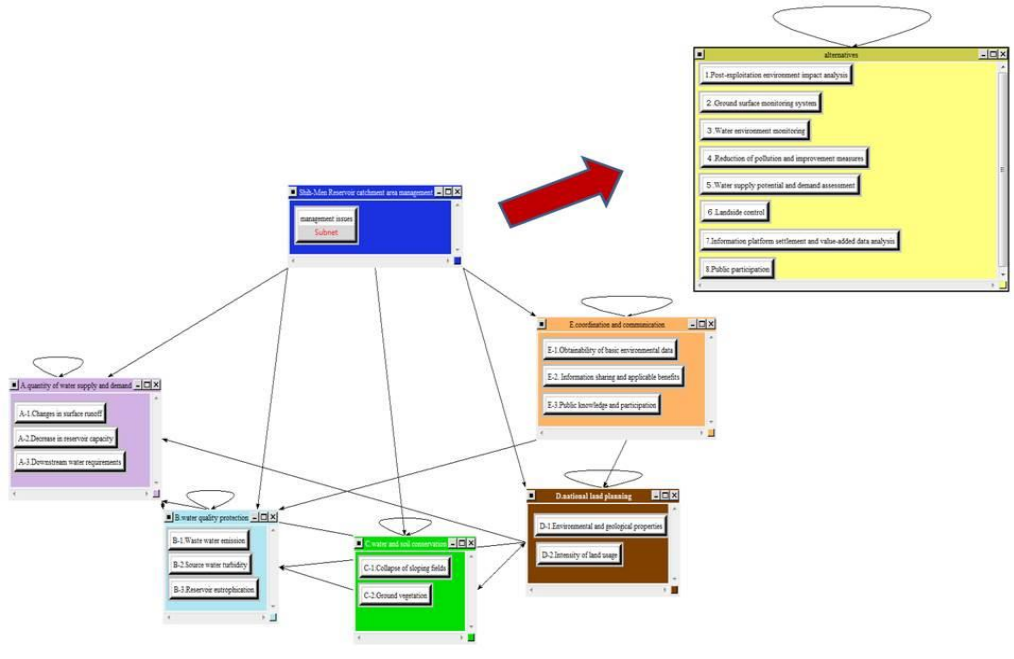

Fig. 3. ANP relationship network map

Table 2. This study ANP final investigative results (by 9 policy stakeholders)

\begin{tabular}{|c|c|c|c|c|c|}
\hline Criteria & Normalized ratio & Factors & Normalized ratio & Alternatives & Normalized ratio \\
\hline \multirow{3}{*}{ A. } & \multirow{3}{*}{0.223850667} & A-1 & 0.039009292 & \multirow{2}{*}{$\begin{array}{l}\text { 1. Post-exploitation environment } \\
\text { impact analysis }\end{array}$} & \multirow[t]{2}{*}{0.1819701} \\
\hline & & A-2 & 0.095333226 & & \\
\hline & & $A-3$ & 0.089508141 & \multirow{2}{*}{$\begin{array}{l}\text { 2. Ground surface monitoring } \\
\text { system }\end{array}$} & \multirow[t]{2}{*}{0.102935} \\
\hline \multirow{3}{*}{ B. } & \multirow{3}{*}{0.177465} & B-1 & 0.066628759 & & \\
\hline & & B-2 & 0.082405215 & 3. Water environment monitoring & 0.1376381 \\
\hline & & B-3 & 0.028431028 & \multirow{2}{*}{$\begin{array}{l}\text { 4. Reduction of pollution and } \\
\text { improvement measures }\end{array}$} & \multirow[t]{2}{*}{0.0926468} \\
\hline \multirow{2}{*}{ C. } & \multirow{2}{*}{0.235567444} & $\mathrm{C}-1$ & 0.167162434 & & \\
\hline & & $\mathrm{C}-2$ & 0.06840501 & \multirow{2}{*}{$\begin{array}{l}\text { 5. Water supply potential and } \\
\text { demand assessment }\end{array}$} & \multirow[t]{2}{*}{0.0260503} \\
\hline \multirow{2}{*}{ D. } & \multirow{2}{*}{0.283278667} & D-1 & 0.092976636 & & \\
\hline & & D-2 & 0.190302031 & 6. Landside control & 0.0455706 \\
\hline \multirow{3}{*}{$\mathrm{E}$. } & \multirow{3}{*}{0.079838111} & E-1 & 0.018315917 & \multirow{2}{*}{$\begin{array}{l}\text { 7. Information platform } \\
\text { settlement and value-added data } \\
\text { analysis }\end{array}$} & \multirow[t]{2}{*}{0.1391923} \\
\hline & & E-2 & 0.024730024 & & \\
\hline & & E-3 & 0.036792118 & 8. Public participation & 0.2739964 \\
\hline
\end{tabular}

Regarding this example of management of preservation sites, based on investigative results(Table 2), respondents believe that "national spatial planning" is most important in comparison with other aspects with an estimated importance ratio of $28.33 \%$. The second most important aspect is "soil and water preservation", at a ratio of $23.56 \%$, while having "supply and demand of water" and "maintenance of water quality" at $22.39 \%$ and $17.76 \%$ respectively. The ANP survey results all show that of 13 reservoir catchment preservation management influencing factors, the top five relatively important factors are: "intensity of land usage", "collapse of sloping fields", "decline of reservoir capacity", "environment and geological properties" and "downstream water requirements".

International Symposium of the Analytic Hierarchy

Process
Washington, D. C. June 29 - July 2, 2014 
Furthermore, respondents believe that the impact of "land usage intensity" and "collapse of sloping fields" are most significant, at ratios of $19.03 \%$ and $16.72 \%$ respectively. Statistics and analyzed results of the 8 alternative program show that respondents believe "participation of people" to be the primary concern in future management strategies, at $27.40 \%$. Regarding land usage and development, second most being to conduct a complete "review of the impact of development of soil and water resources on the environment", at a ratio of $18.20 \%$. The third being "the construction of information management platforms and benefit analysis", at a ratio of $13.92 \%$; the fourth being "water environment monitoring", at $13.76 \%$; the fifth being "surface environment monitoring system", at $10.29 \%$.

\section{Limitations}

This research uses the Shih-Men reservoir's water preservation area as the research site, but due to limited interview subjects, compilation of documents and related arrangement of conditions, it might not be suitable for other Taiwanese catchments as a whole, but can be of general reference and utility, collaborative planning, and multiple criteria strategizing for reservoir catchments of similar environment to implement in the future.

\section{Conclusions}

This paper utilizes the perspective of collaborative planning of stakeholders for investigation. The ANP survey results show that "national land planning" is the primary problem that the Shih-Men reservoir needs to resolve, and its main influencing factor originates from "the extent of land use". Secondly, "water and soil conservation" is an issue that needs to be of increasing concern, and should develop management strategies for its main influence factor, "collapse of sloping fields". In regard to alternative programs for the management of catchment preservations, respondents believe "public participation" should be of main concern for the management strategies of future water catchment preservation sites, and promote application of management strategies such as "post-exploitation environment impact analysis" and "information platform settlement and value-added data analysis", thus strengthening the result of future planning of water source preservation areas, environmental impact analysis and further follow-up of investigations and management.

This research recommends that the government, when formulating government policies, in addition to relying on professional knowledge, should also clearly define important policy stakeholders, and encourage active involvement, in order to prevent policies be dominated by expert authorities. Only through involvement can policy stakeholders express their rights, interest and viewpoints, and from this obtain a balancing point in policy thinking and set the enthusiastic cultivation of collaborative culture as a goal (Lin ShuiPo, 2011:ch4). Moreover, through the mechanism of collaborative planning, can we confirm the mainstream value of society, not stray from the target, and also effectively combine community resources and promote collaborative public policies.

\section{Key References}

Mitchell, R. K., Agle, B. R. \& Wood, D. J. (1997). Toward a theory of stakeholder identification and salience: the principle of who and what really counts. Academy of Management Review, 22(4), 853-886. 
IJAHP Article: Mu, Saaty/A Style Guide for Paper Proposals To Be Submitted to the International Symposium of the Analytic Hierarchy Process 2014, Washington D.C., U.S.A.

Saaty, T. L. and Saaty, R. W. (2003). Decision Making in Complex Environments (AHP \& ANP), Super Decisions.

Thomas L. Saaty, (2001). Decision Making With Dependence And Feedback-The Analytic Network Process, RWS Publication.

Water Resources Agency, Ministry of Economic Affairs, R.O.C (2009a). Strategic Planning of Water Quality Management within Shihmen Reservoir Catchment.

Water Resources Agency, Ministry of Economic Affairs, R.O.C (2009b). Strategic Planning of Management Techniques for Water Quality and Quantity Protection $\operatorname{Areas}(1 / 2)$. 